\title{
The Mitigation of Transient Poverty: Agenda-Setting Discourse in the Formulation Process of the Policy of Poverty Alleviation in Indonesia
}

\author{
Djonet Santoso \\ Diponegoro University, Indonesia \\ E-mail: prodidap@gmail.com \\ Sri Suwitri \\ Diponegoro University, Indonesia \\ E-mail: sri_suwitri@yahoo.co.id \\ Paulus Israwan Setyoko \\ Jenderal Soedirman University, Indonesia \\ E-mail: prodidap@gmail.com
}

Soesilo Zauhar

Brawijaya University, Indonesia

E-mail: prodidap@gmail.com

Received: October 16, 2016 Accepted: November 22, 2016 Published: November 23, 2016 doi: $10.5296 /$ jsss.v4i1.10352

URL: http://dx.doi.org/10.5296/jsss.v4i1.10352

\begin{abstract}
As a population group with income and/or expenditure that is alarmingly close to the poverty line, the position of transient poor can be very unstable. They are in a constant vulnerability of falling under the poverty line with every critical situation that arises, which are affected by disasters, social conflicts, termination of employment, and/or changes in public policy
\end{abstract}


especially in the economic sector. Up to 2015 , poverty alleviation programs in Indonesia is divided into four clusters: social protection, community empowerment, small scale credit, and pro-poor supported program. Strangely, there is not a single clause in any of the four clusters that elaborates the policy schemes that addressed to the transient poor. The research is aimed to triangulate the position of transient poor groups in the poverty alleviation policy framework. Additionally, this research is also aimed to clarify the agenda-setting process in the formulation of poverty alleviation policy that neglects the transient poverty issues mitigation. The methodology used in this research is descriptive qualitative. Two major findings can be derived as the conclusions from the research. Firstly, the position of transient poor population is not included in the poverty alleviation policy scheme. The existing policy alleviation scheme does not accommodate the needs and tailored approach to cater to transient poor population. Secondly, the oversight to catering to transient poor population starts even from the agenda-setting in policy formulation processes. This is seen from the fact that transient poverty issues are not exposed to the problem stream, policy stream, and political stream that utilizes policy window to discuss transient poor issues throughout the agenda-setting.

Keywords: Transient poverty, Public policy, Agenda-setting

\section{Introduction}

The product of any public policy process is the direction and measures to solve problems experienced by the public. An agenda-setting analysis is the entrance to understand and explain the effectiveness of a public policy, including poverty alleviation policies. Various problems in the implementation of poverty alleviation policies cannot be separated from how policies are formulated. The earliest stages of the process that determines the overall poverty policy formulation lies on the agenda-setting process, the process of accumulation of recognition of poverty issues and problems are to be discussed, debated, and embedded into the public policy agenda. Thus, explaining the effectiveness of poverty reduction policies should not be satisfied merely by understanding the process of its implementation course, but there is a need to undergo a deep understanding of how the public issue of poverty is recognized, accepted as a public problem, and included in the agenda of policy formulation.

The term of transient poverty refers to or describes the problem of poverty experienced by a group of people by their ability to finance their expenditure to be within proximity, slightly below or above, and move around the poverty line (Ravallion, 1988). Transient poverty is a fluctuating condition, up and down close to the poverty line that are experienced by families and individuals. This movement can only be identified by comparing two or more survey periods. Ravallion (1988) laid an essential foundation to the understanding of the transient poverty phenomena that distinguishes it from that of chronic poverty. To better explain the phenomenon of transient poverty, Ravallion (1988) divides the poor into three groups. The first group is the population group that are identified as always in the same position under the poverty line in each survey period. This group has been commonly referred to as the population group of the chronic poor or very poor. Second, a group of poor people that are previously identified poor yet still only slightly below the poverty line, and identified only slightly above the poverty line in the next survey. This population group is not always under the poverty line. These groups have been experiencing upward movement although in another 
survey period may be identified under the poverty line again. Third, a group of not poor people that are previously identified not poor slightly above the poverty line, and identified slightly below the poverty line in the different survey period. The population group are not always above the poverty line. These groups have been experiencing downward movement although in another survey period may be identified above the poverty line. The second and third group is referred by Ravallion (1988) as the transient poor population.

There is no available data on the transient poor population in existing national statistical data. The available data merely illustrates the number of poor population under the poverty line. The World Bank estimates that in 2014, the number of transient poor population in Indonesia ranges from 28 to 30 percent, or approximately 64 million people. The official number of poor population in the same year is noted at 11 percent. It means that the number of transient poor population is almost three-fold.

Poverty reduction is achieved through various affirmative actions that are implemented through four cluster programs, namely 1) assistance and social protection, 2) community empowerment, 3) empowerment of micro and small businesses, 4) pro-people program. The Handbook of National Team for Poverty Alleviation Acceleration (2010) elaborates the strategies for all related poverty programs. However, those strategies don't explicitly mention the scheme which is devoted to handling the transient poor population groups. Poverty programs in the 2010-2014 period did not touch the existence and needs of transient poor population groups. It can be underlined from this fact that the government is neglecting the existence of the transient poor population. The issue is not at the level of policy implementation, it is at the policy formulation stage, especially in the agenda-setting process.

Poverty alleviation policy does not clearly state to address the mitigation of transient poverty, both in substance and schematics. Two research questions to be answered are: a) where is the actual position of the transient poor population in poverty alleviation policy scheme?, and $b$ ) what is happening in the agenda-setting process of poverty reduction policies that causes the problem of transient poverty is not included in the policy?

\section{Theoretical Framework}

Many poverty alleviation-related policies have been launched and implemented through related ministries. The basic problem is that the content of such policies does not show the concern on the issue of transient poverty. The empirical, normative, and theoretical exposure presented in the introduction part suggested that the ignorance of transient poverty occurs in the agenda-setting stage of the public policy formulation process. There are three arguments awakened from these allegations. First, the existence of the phenomenon of transient poverty may indeed not be understood by the actors involved in the policy formulation, so as not to understand it is not taken into account, and finally ignored in the process of agenda-setting. Second, there is a possibility that transient poverty problems do not meet the criteria as a matter of public record so it does not need to be scheduled in the formulation of public policy. Third, there may be tremendous pressure both internally and externally in the phase of policy formulation so that the actors are not able to firmly stand to develop policy content that guarantee the achievement of effectiveness, efficiency, and economics of poverty policy implementation. These arguments will be clarified through discussion of this literature review. 
Public policy is the pulse of the governance process (Santoso, 2010, p. 4). Within the framework of democracy, the policy process brings together a country that has the legitimacy to make a public policy with the sovereignty held by the people or citizens. Following this line of thinking, the most basic questions about a policy is how far the government 'links' with the public will? In the process of public policy formulation, the first determinant linkage was present in the agenda-setting process, which means the stage of preparation of the agenda. Policy agenda is a list of issues or matters of serious concern of policy actors (Kingdon, 2014).

The analysis of the process of agenda-setting processes discusses how certain interest groups are trying so hard to enter public issues and problems on the agenda, and how groups of other interests trying to prevent the same issues and problems into the policy agenda. An important part of this process is not only on how the issues and problems of the public is put on the agenda, but also how these issues attracts public attention and shifts other issues. The problem of this study is the exclusion of the issue of transient poverty from the formulation of poverty alleviation policy. The issue of transient poverty is allegedly ignored in the agenda-setting. Therefore, the discussion on agenda-setting is fundamental, especially regarding the processes of agenda-setting. Discussion on the agenda-setting parse conceptions of how agendas are prepared, how the relationship between interest groups and power with agenda-setting and also between problem formulation and agenda-setting, and finally how to clarify the substance of the public problem in the process of agenda-setting.

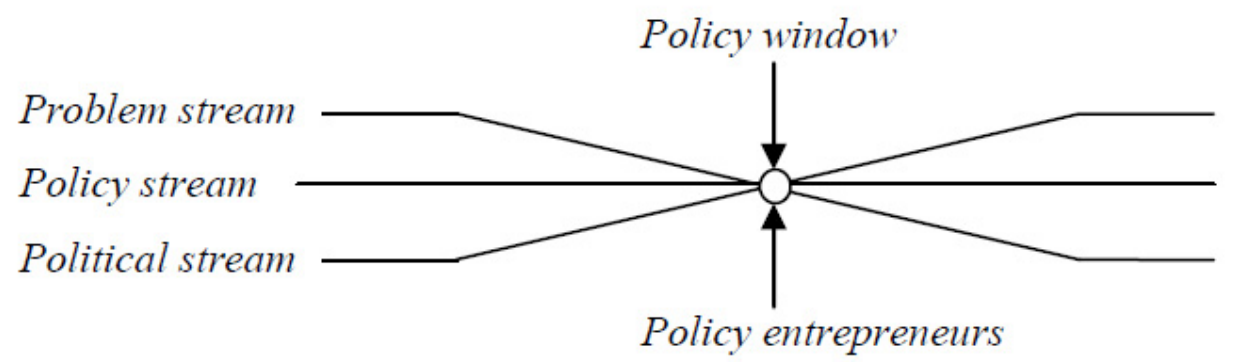

Figure 1. Multiple Streams Framework by Kingdon (Source: Kingdon, 2014)

Framework for multiple-streams according to Kingdon (2014, pp. 166-167), is an analytical framework to assess the process of preparing the agenda. Kingdon believes that the product of public policy is a function of encountering public problems, policy process, and political intervention. The framework is very appropriate to explain why the problem of transient poverty is ignored in the agenda-setting phase in the formulation process of poverty reduction policies. Why policy makers did not recognize transient poverty issues, how a public problem can be recommended as policy agenda, and how the political situation plays an important role in the processes of agenda-setting.

In addition to describe the encounter of the three streams, agenda-setting analysis also includes an important role of the policy window and the policy entrepreneur. The core of the 
framework Kingdon (2014, pp. 172-173) is in the encounter of three streams in such condition, point, momentum, and a certain time, called policy window. Policy window is a point of opportunity that opens at a certain time, intentional or unintentional, which can be used to advocate issues to be recognized by the public and policy makers. Each stream does not intersect each other until the window is open, opening up more opportunities for a public problem to be recognized by of all parties, and bringing the problem to enter to the policy agenda discussion. In the opening phase of this policy window, the role of policy entrepreneur is strategic in managing the encounter of the three streams to discuss the public problem for policy change.

Kingdon (2014, pp. 109-110) distinguishes between the conditions and problems. The condition is a situation that happens in everyday life. Transient poverty can be used as an example of this condition. Transient conditions evolves into a problem when there is an urgency to respond to the condition, because it gives a very broad impact for the community. Kingdon (2014, pp. 109-110) states that in order for a condition to be considered as a problem, people must feel that something must be done to change that condition. Issues arising from this situation is that policymakers are composed of many parties who have different viewpoints so that is not easy to attract their attention to the problem. Kingdon (2014, pp. 90-99) describe three factors that can foster an issue to gain the attention of policymakers, that are indicator, focusing event, and feedback. Indicator is a measure used to assess the scale and changes of a problem. The statistical data can be used to assess the profile, character, and the critical point of problem. The changes that occur whether in the form of an increase or decrease, differences, and the tendency of the data over time and from one data source to another can indicate success or the failure of a public policy. The attention of policy makers will be drawn through the presentation of data that is alarming, showing the weakness and failure of policies, especially if it will affect the public confidence in the ruling government. Policymakers use indicators for two purposes, namely to access the magnitude of the problem and to be aware of changes in the problem (Kingdon, 2014, p. 94). Feedback according to Kingdon (2014, pp. 100-102) also can be used to get the attention of the policy makers. Feedback can be the result of review, monitoring, and evaluation of programs implemented performance-related. Feedback is very important if the performance of the program experiencing slowing down, decrease, weaken, or did not work as planned. Feedback can also be derived from the people who complain about the program or policy was treated unfairly by a policy, or feel neglected by policy.

Policy stream is associated to the process of linking the problem with a solution. Policy rational of policy flow includes various efforts to find solution to one or many problems (Kingdon, 2014, pp. 116-145). In the policy area of the steam, academics, technocrats, and other policy actors are trying to convince bureaucrats or politicians through argumentation of solutions to the existing public problems. According to Kingdon (2014, pp.117-138) there are eight elements in the policy stream, which is an alternative, community policy, advocacy, policy entrepreneur, technical feasibility, value received, the political feasibility and consensus.

The policy community consists of people and interest groups who pays attention to policy related issues, including academics, consultants, or policy analysts. They offer ideas or 
alternative solutions to resolve the problem. Community policies have extensive interaction, especially with a group that has the same ideas (Kingdon, 2014, pp.117-118). Policy stream is an area where various policy alternatives articulated. Actual policy makers are aware of many public issues, but due to limited time and resources, they are only able to accommodate a limited number of solutions.

Political stream consists of several components described by Kingdon (2014, pp.145-152) including (a) national mood (the climate of public opinion), (b) power of political organizations (parties, legislative politics, and pressure groups), (c) results of the election (public officials and political turnover associated with elections cycle), and (d) establishment of consensus (bargaining and advice). Kingdon (2014, p.145) uses the term "politics" in reference to the reaction and attention of politicians to the wishes of voters, pressure from interest groups, and participants in the elections. The central idea of the political groove is to incorporate the dynamics of political factors in the policymaking process. Substitution officials and the election results as a trigger political groove, can be used to push an issue to the agenda of the government, because usually this change leads to differences in issues and agendas. Kingdon (2014, pp. 153-155) states that changes and replacement of officials is the most powerful time to consider the proposed new policy. Bureaucrats generally seek to maintain their position. Therefore, they are always trying to have new proposals to support their position.

The model is looking at multiple streams in regards to the important role of policy entrepreneur in determining the agenda-setting (Kingdon, 2014). Entrepreneurs are people who have the power of innovation that can take advantage of all opportunities available and dare to bear the risk. Sabatier and Smith (1999) uses the concept of policy broker for this role as parties with very active and responsive to undertake a variety of ways to bring an issue into the public policy agenda. The term policy entrepreneur was first proposed by Kingdon (1984). Policy entrepreneur is defined as actor, whether inside or outside the government, groups, or individuals, who have the willingness to invest resources, both time and energy, reputation, and sometimes money to support, carry, accompany and fight for policy proposals. Kingdon (2014, p. 204) mentions further that although the main purpose is for the advocated policies approved, policy entrepreneur also has a strong motivation to get satisfaction, or even the greatness of his name, fame, job security or career promotion. Very clearly, Kingdon (2014, p. 122) defines policy entrepreneurs as "advocates for proposals or for the prominence of ideas". Policy entrepreneurs are basically working to change the direction and political flow to be fitted to his ideas and policy proposals.

Policy entrepreneurs are very smart in using certain indicators to develop public opinion, to divert the issue, to direct the conversation, and to move attention from one issue to another issue, and especially to make sure that policymakers put the proposal into the policy agenda. Furthermore, Kingdon (2014, p. 123) argues that perseverance is the most important characteristic of a policy entrepreneur. Becoming a member of several organizations is a better value for policy entrepreneur in managing issues and problems from one place to another, from one time to a more appropriate time (Baumgartner \& Jones, 1993, p. 110). Policy entrepreneurs are people who are dynamically seeks to implement policy change by using a network, develop public opinion, directing the policy debate, and develop coalitions. 


\section{Macrothink}

The main role of policy entrepreneur is managing the stream to encounter problems, policy stream, and political stream, so that the window policy (policy window) opens and allowing them to push an issue on the agenda of the government for discussion. According to Kingdon (2014, pp. 172-173), policy entrepreneurs are always working to connect all three of these flows together, unhook them, and then reconnected in a different way. Policy window is an opportunity for supporters of the proposed policies to encourage the solutions they propose, or to encourage obtaining attention to the special problems they propose. There are several causes of the opening of policy windows (Kingdon, 2014, pp. 166-170), i.e. a change in the political flow (such as changes in administrative agencies or legislative), a shift in ideology which then provide an opportunity for the preparation of the agenda, the economic crisis, as well as focusing on events such as natural disasters or energy crises. Policy windows shut because of a problem rated as something routine and no event is to encourage the opening of the window. The framework Kingdon (2014) illustrates show how difficult it is to open the window. A policy window will only open when the problem stream, stream policy and political streams meet. The role of policy entrepreneur to be very strategic in managing this meeting to come up with a new policy agenda that aims to revise and enhance existing policies, or for the new policy.

In a policy argument window, the right time can be a key factor influencing policy entrepreneurs. In the context of the problem of transient poverty, the government is likely ready to cope in the early period of his rule, or just when they're in the position of running out of ideas and energy to maintain power. Efforts to persuade the government to address the problem of transient poverty at other times when there is no public pressure urging him likely to fail no matter how rational arguments to address the problem. In this situation, Wilson (2006) states that the government is more open to new thinking at certain times than other times. When negotiations on policy issues at an early stage and thought it was still molten, it is easier to influence than later when thought has hardened. Further, Wilson (2006) underlines that the momentum of the discussion of a problem also have limitations both in the executive and parliament. The cabinet sessions schedule has limited space for discussion with little time for competition among ministries to gain the attention of the president.

\section{Research Methods}

The research method chosen in this study is the descriptive qualitative method. As part of the qualitative method, descriptive qualitative approach includes the construction of social reality and cultural significance, focusing on the process of interactive, events, authenticity, not value-free, theory and data is integrated, situational or contextual, and the involvement of the researcher (Creswell, 1994). Qualitative methods according to Creswell (2013) has the characteristics of natural setting, researcher as a key instrument, multiple sources of data, the inductive analysis of data, of participants' meaning, emergent design, theoretical lens, interpretative, and holistic account.

Using the characteristics of the guidelines submitted by Creswell (2013), the qualitative study uses natural setting or the natural environment of the parties interviewed, not collect in one room (except during the focus group discussion), and not engineering any situation. Researchers as a key instrument to collect their own data through documentation and interviews with informants. Analysis was performed with the guidelines of data from various 
sources, not just one source only, through interviews and documentation. This qualitative study builds patterns, categories, and themes from the bottom up (inductive), by processing the data into information units that are more abstract. This inductive procedure guiding implement chronological stages of research. Researchers focus on efforts to understand the meaning conveyed by the informant about a problem or issue research, informants' meaning and not meaning conveyed by the researcher or the other authors in the literature. However, this study is interpretative, researchers make an interpretation of what is seen, heard, and understood.

\section{Discussion}

Poverty has always been a major issue in every period of government. There are four fundamental elements that relate to and affects this, namely data and substance of the problem of poverty itself, how actors of poverty alleviation policy see the problem, how political actors understand the problem, and how all of the parties exploit loopholes in policies and pushes the issue of poverty to become policy product. Synergy of these four elements have colored the product of poverty alleviation policies in each government period. The indicators of success in poverty reduction efforts are shown by statistical data in the number and percentage of poor people over time. By not ignoring the influence of previous policies, this study chose to focus on policy product in the period of 2005-2014 government.

This paper starts from an assumption that the transient poor population are not explicitly dealt with in the public policy of poverty alleviation, both in substance and schematic. Thus, the discussion is about the presence of transient poor population and agenda-setting processes that 'ignores' the mitigation of transient poverty problems. First, the description in this section will clarify the real position of transient poor population in the scheme of poverty reduction policies. Second, this section will clarify what happened in the agenda-setting process of poverty reduction policies so that the problem of transient poverty is not explicitly addressed. This clarification uses the Multiple Streams framework from Kingdon.

1. Position of the transient poverty in the poverty reduction scheme

The weak recognition of the problem is due to a lack of complete and comprehensive data about the transient poor population. In 1988, Ravallion has laid an important basis of the concept of transient poverty that distinguishes it from general understanding of chronic poverty. Transient poverty is a moving condition experienced by households and individuals who are around the poverty line, above or below, by comparing statistical data of two or more survey period. Very clear, Ravallion (1988) underlined that the answer to the question of who, how, and why is vital in order to understand correctly the phenomenon of transient poor. Understanding the phenomenon is important to understand the problem. The moving up of poor people as well as their moving down to under the poverty line can be assumed as the implications of public policies that affect their revenues or expenditures. By recognizing the 'who', how, and 'why', then the poverty reduction policies would be well prepared and more effective targeted.

The next question is about the data. To answer this question, the United Nations Statistics Division (UNSD, 2005) confirms that, in general, poverty can be distinguished two types; those where people are always poor (chronic, static), and where people who had a poor result 


\section{Macrothink}

from events that impoverish both from outside and from within (transient, dynamic). Data for the chronic poor population can be easily found in the cross-sectional data, while the transient poor phenomenon requires continuous periodic data, time series, or longitudinal data. Cross-section data, data that were collected at a specific time (at a point of time), aim to describe the state/activity at that time. While longitudinal data is the data collected by a certain period, from time to time with the direction of time towards the future, aiming to provide an overview of the development of a state. It can be noted from this description, that longitudinal data can provide answers amid the 'who' and can give more detailed description of the 'why'. A more detailed understanding of this may provide more concern for policy substance of the problem of poverty in each category or deciles. The policy could also better to ensure the accuracy and utilization goals. With this method, the problem of recognition is expected from the policy makers on the issue of transient poor population groups will be better, bring it to the level of preparation of the agenda at the policy formulation stage. This method ensures that more transient poverty problem is no longer neglected.

From various documents and in-depth interviews, the study notes that the preparation of poverty reduction policies turned out to be based on cross-sectional data; data collected at a specific time (at a point of time) which describes the condition of poverty in that time. Poverty data is published by the Central Board of Statistics (CBS) includes data of macro and micro data. The macro data is data that only shows the aggregate number and percentage of poor population, generated from the results of the National Economic and Social Survey (NESS). While poverty micro data is gathered by using the criteria of access to basic services by the population. Micro data concerning the condition of this population resulting from the activities of the Social Protection Program Data Collection (SPPDC). The poverty rate which has been used by the central government is calculated using NESS data. The macro poverty rate illustrates macro conditions and used for the benefit of macro planning. Because of its strategic function, starting in 2011, the CBS adds the intensity of survey activity to get the data of macro poverty rate to be renewable by 4 (four) times survey in a year. At the same time, in addition to the macro data of poverty rate, the CBS also conducts census on the target data through SPPDC to produce micro data of poverty rate once in every three years. The figure of the micro data is used for planning of micro programs/activities, especially for targeted programs/activities. The existing micro data of poverty rate is the result of 2005, 2008, and finally 2011 survey. In contrast to the previous data collection, in 2011 the CBS made changes in data collection methods by identifying $40 \%$ of the population with the lowest income.

The problem of recognition of transient poverty can only be realized through the analysis of longitudinal data. With longitudinal method, the situation, abilities, and needs of each individually poor household can be better understood. Assuming that the conditions of life of every person is dynamic, then the situation of poor households or individuals are also dynamic. This condition will be different from one time to another, either experiencing improvement or deterioration. It is underlined that understanding the dynamic condition of poor households and individuals should be used as the basis for the preparation of poverty reduction policies.

This study noted that the answer to the question of why the problem of transient poverty was 
ignored in the scheme of poverty reduction policies originates from the cross-sectional data bias owned by the CBS. Cross-sectional data of poverty do not have the ability to explain to policymakers in the policy formulation stage, that there is a dynamic change in conditions of poor people in different time periods, as well as dynamic variables that affect it. Cross-sectional data may be used to describe the relationship between two variables of poverty, but cannot be used to show the direction of the causal relationship between these variables. While longitudinal survey though more complex and require greater cost, more reliable in searching for answers about the dynamics of change and development of the poor families and individuals (UNSD, 2005).

This study notes an important fact that actually the CBS have already detected the presence of transient poor population from their cross-sectional data, that there are some number of people who move to add and also move to reduce the number of people in each category of the poor population. That is, in fact that transient poverty phenomenon has been detected when comparing data between two or three the survey period. However, the understanding of the existence of transient poor population remains only at understanding the aggregate number of poor people who differ in some period of the survey, not on a detailed and deep level of understanding on population dynamics, moving or transient population. Therefore, it is understandable that a label is stamped to groups of the population that experience changes in the aggregate amount, and as a guide all parties, the CBS uses the term vulnerable poor. The concept of vulnerable poor, however, is very different from the understanding of transient poor. Vulnerable poor describes the condition of the 'vulnerable' to an immediate decline. Vulnerable to decline connotes people who was previously above the poverty line in the previous survey period, and fell under the poverty line in the next survey. Or it could connote the population that previously had been under the poverty line in the previous survey period, falling more deeply under the poverty line in the next survey.

Research also noted that one of the vital factors of mis-targeting of poverty reduction policies, and also the neglect of poor transient group, are because of unavailability of 'by name by address' data. This data is very tightly closed, confidential, so nobody can identify who are the poor population. It is very strange that in an area of neighborhood, for example, none of the residents know who are neighbors recorded as 'poor' in the statistics. The CBS argues that this secrecy is the mandate of the provisions of Article 21 of Law No. 16 of 1997 on Statistics which states that organizers of statistical activities required to guarantee the confidentiality of the information obtained from the respondents. Under this provision of this Act, CBS must ensure the confidentiality of personal data (individual information) collected. The CBS merely present the aggregate number of poor population and keep by name by address information closed. This principle is conflicting with the needs for individual information for longitudinal analysis purpose.

There are three conclusions can be noted from the discussion of these results (see Figure 2). First, the existence of transient poor population is not easily found in the existing statistical data. This is because the CBS only uses cross-sectional data in calculating the number of absolute and relative poverty. The CBS Data category of the absolute and relative number of population groups that are very poor, poor, near poor, and other vulnerable poor are aggregate data counting of a one-time period of survey. Attention to the poor population movements 
between categories or classifications can only be seen from a comparison of the aggregate amount between two or more survey period. Longitudinal method that can deliver more detailed data of 'who' and 'why' move from one survey period to the next survey period is not used in the surveys. Second, there are substantial differences between the understanding of the concept of vulnerable and transient poverty. The difference of understanding is what causes poor transient data is not found in CBS data. This also explains why the handling of poor transient population is not found in the scheme of poverty reduction policies. The CBS also argues that the longitudinal method was not used in this argument because the cost of conducting the method is very expensive. Thirdly, the closure of the data by name by address hides behind the Law on Statistics. The existence of the transient poor only to the extent of being known but do not know the 'who' and 'why'. Because they do not know the 'who' and 'why' then indeed the special handling of transient poor group cannot exist. It can be concluded, that the handling of transient poor population groups is neglected in the substance and scheme of policy of poverty alleviation.

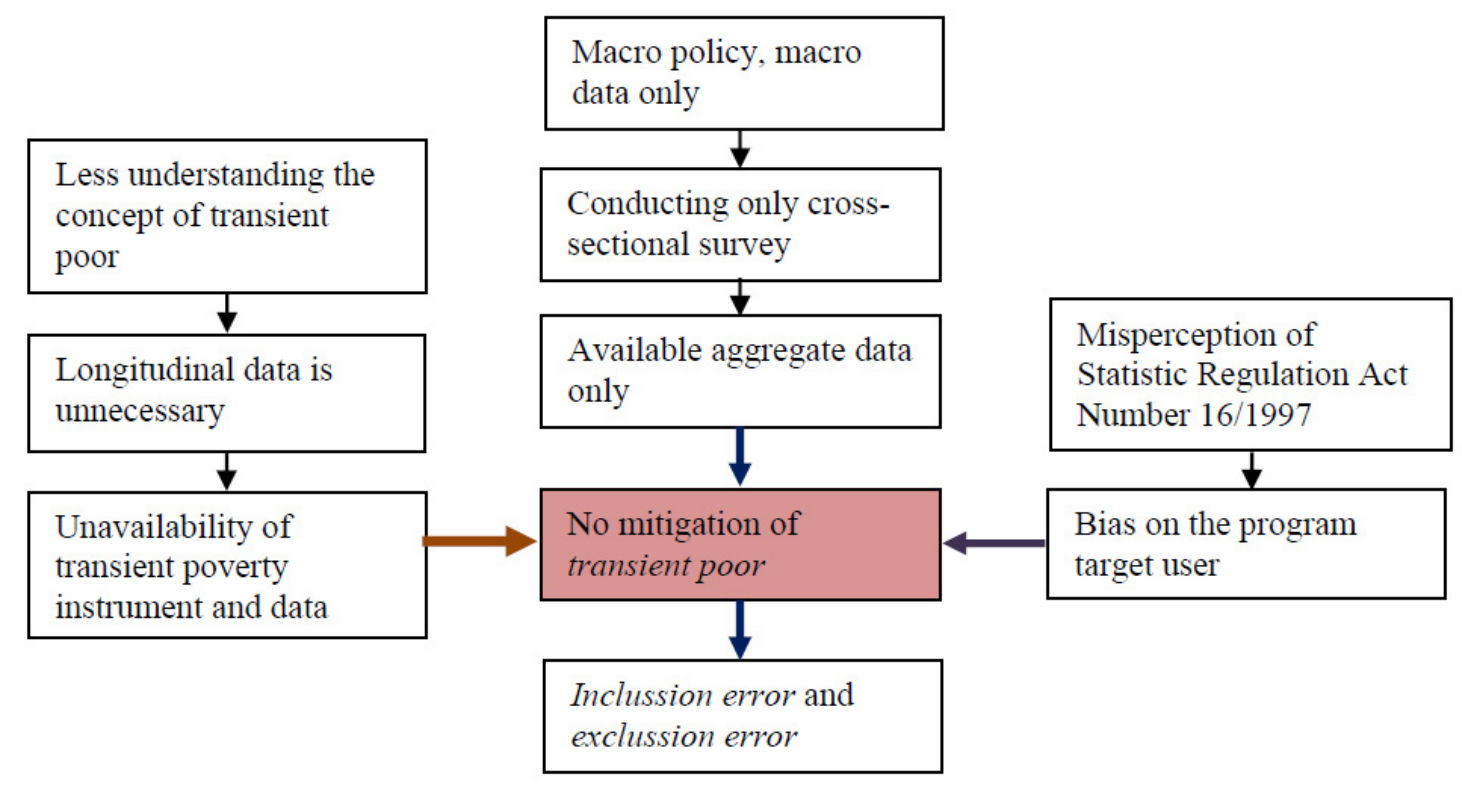

Figure 2. Existing condition of the position of transient poor population in the scheme of poverty of poverty alleviation

The process of agenda-setting of the poverty reduction policy

If the longitudinal data of the transient poor does not exist, does it mean that the agenda-setting process could not include transient poverty issues into the discussion? If the reference of Ravallion (1996) is applied, then the answer is no, it cannot, because the development of policy model depends on data. That is, academically, the logical linkage of problem - measurement - the data - and the policy model become disconnected. However, it is very common that this academic argumentation may be denied by political logic. There are many possibilities that can occur in the process of political decision-making. In addition to 
the problem of data, there is policy stream, political stream, policy entrepreneurs, and policy opportunities as indicated by the close and open of the policy window. In the second part of the discussion, we will discuss about the process of agenda-setting of public policies to reduce poverty. This discussion will clarify the agenda-setting process that happens to answer the research questions why the handling of transient poor is ignored in the scheme of poverty reduction policies.

The bias perceptions of Article 21 of Law No. 16 of 1997 on Statistics which states that organizers of statistical activities are required to guarantee the confidentiality of the information obtained from the respondents may be appointed as full political interests. Based on the mandate of this Act, the CBS must ensure the confidentiality of personal data (individual information) collected from respondents. With such confidentiality argument, the CBS guarantees that all data is not accessed by the individual, system are not entitled to access. This point precisely becomes the arena of political interests, who and for what purpose the parties can and cannot access data. Data is a political commodity. Every decision and public policy depends on the data. Therefore, every decision and public policy is the product of a political process to fight, prevent, inhibit, or even hide a lot of interest. An argument as an expression of interest is always based on research data that is owned.

Table 1. Economic and political interests in the poverty reduction policies

\begin{tabular}{lll}
\hline Interest of the transient poor & Economic interest & Political interest \\
\hline $\begin{array}{l}\text { Their specific problem to be } \\
\text { handled }\end{array}$ & Opened data & Closed Data \\
$\begin{array}{l}\text { Every single family and } \\
\text { individual having different } \\
\text { problem from time to time }\end{array}$ & $\begin{array}{l}\text { Cross-sectional macro data } \\
\text { similar problem from time to }\end{array}$ & Cross-sectional macro data \\
time & problem from time to time
\end{tabular}

Table 1 explains the difference between the interest of the transient poor, in terms of 
economic interests and political interests. Transient poor groups want their problems to have immediate attention and solution. They hope there are some forms of special programs that provides sustenance to their survivability amidst the economic shocks that often happen so it does not fall below the poverty line. However, this voice is not completely caught by policymakers because they use cross-sectional macro data. Economic and political concerns over using macro data for the future orientation and consider the needs of the entire population of transient poor groups is similar to the needs of chronic poor groups. Because they think these two groups have similar needs, the resolutions are the same as the method of direct assistance. Transient poor population also expects immediate relief, but they also require special assistance aimed at improving their capacity to always survive, it is not merely social assistance as it is for the groups of chronic poor.

The economics and politics of logical thinking can just continue to be developed, but the logic of target population program should also get attention. Transient poor population prefer a participatory approach that could be directly involved in any attempt to increase its capacity. Meanwhile, the economic interests show preference on the formal legal approach in its approach because it involves investments for poverty program of national and even international. On the other hand, political interests cannot be separated from the interests to manage supportive voice to get and stay in power. Poverty reduction policies are part of other steps in an effort to manage supportive voice for the status quo. Therefore, political interests see the poverty line as a marker of performance, can make performing well, or vice versa. This is indicated by the head of local government reports that deliver varies and different poverty reduction performance according to his/her interests.

There are four conclusions that can be noted from the discussion of the agenda-setting process of public policy to reduce poverty. First, there is no national consensus to eradicate poverty down to its roots. Confusing policies, generalization policy for all layers in the classification and categorization of the group 40 percent of low-income residents, shows the weakness of the consensus. Second, the fact that the approach that still uses cross-sectional data to guide policy formulation the CBS indicates that the program targets was performed centrally using only data centers. Because it uses a data center, then the policy initiatives and programs may not use data other than the centralized data. Because data is centralized, then the drafted policies are central-driven. Third, the political agenda-setting process occurs centrally. This can be seen in Presidential Decree No. 13/2009 concerning the Coordination of Poverty Reduction and Derivatives Regulation No. 34/2009, Presidential Decree No. 15/2010 on the Acceleration of Poverty Reduction and Derivatives Regulation No. 42/2010. Fourth, in the context of societal context, there is a long process of formation of culture in all layers of community life. This indicates that tackling the problem of poverty can be best done layer by layer.

How far is the government 'linked' with the public will of the people? In the process of public policy, the first determinant of linkage was present in the agenda-setting process, which means the drafting stage of public policy agenda. Analysis of the process of agenda-setting processes discusses how certain interest groups are trying so hard to submit public issues and problems on the agenda, and how groups of other interests tries to prevent these issues and problems into the policy agenda. The important part of this process is not 
only on how the issues and problems of the public are on the agenda, but also how these issues could attract public attention, shifting other issues. Discussion on the agenda-setting parse conceptions of how agendas are prepared, how to clarify the substance of the matter public in the agenda-setting process, and how the relationship between interest groups and the agenda-setting power.

Transient poverty issues have been neglected in the agenda-setting of poverty reduction policies. The formation of the arguments in the agenda-setting theories is the result of deductive and inductive reasoning with different settings. Specifically, this discussion will be articulate, to criticize, and to reconstruct the framework of multiple streams of Kingdon. The purpose of the discussion in this section, firstly, is to contribute new ideas for the improvement of the theories agenda-setting theory in particular and public policy in general. Secondly, to provide a practical contribution to enhance poverty reduction policy that accommodates the complete handling of chronic poverty and transient poverty.

From the empirical data in the field, the study notes that the problem of transient poverty has not become part of the mainstream. The concept of transient poverty is still not completely understood by policy makers and stakeholders. This concept is very different from the CBS's concepts of almost poor, the vulnerable poor, or near poor. Those concepts are just a grouping of static depictions of the poor as a spot-check survey respondents with different or inadvertently selected the same from one period of the survey with another survey period. While the concept of transient poverty refers to poor conditions who move from one survey period to another period of the survey. This movement is not only shown by the survey on aggregate data such as spot-check, but complete with a data 'who', 'how' and 'why' of the poor move. To obtain such data, the respondent should be the same for the purpose of comparing the conditions of the respondents of the survey period to another period of the survey.

The same thing happens in the territory of policy stream and political stream. The problem recognition on transient poverty problem does not occur in these two streams. A weak understanding of the concept of transient poverty has led to all parties in the formulation of poverty reduction policies ignore this phenomenon. A weak understanding of the concept is also due to the fact that there are no measurements, data, and modeling of transient poverty problem. The use of statistical data of 40 percent of the lowest income population by CBS, National Board of National Development Planning, and National Team for Poverty Reduction Acceleration has become a curtain covering the presence of transient poverty phenomena to be in recognition. The mainstream formed by this fact is that the task of policy makers to just only to reduce poverty statistically. The root cause of the poverty problem was generalized. Therefore, there are some programs that overlaps among the ministries because all of them wanted to wipe out 40 percent of the lowest income population. As a result, many poverty reduction programs are misplaced. The concept of transient poverty requires a precise explanation about the real causes of moving poverty conditions, the unique characteristics of each state, as well as the macro and local situation that contributed to the move of poor condition. The absence of a policy paper on the subject of poverty has increasingly distanced transient phenomenon to be recognized by the parties in the policy stream and political stream. 

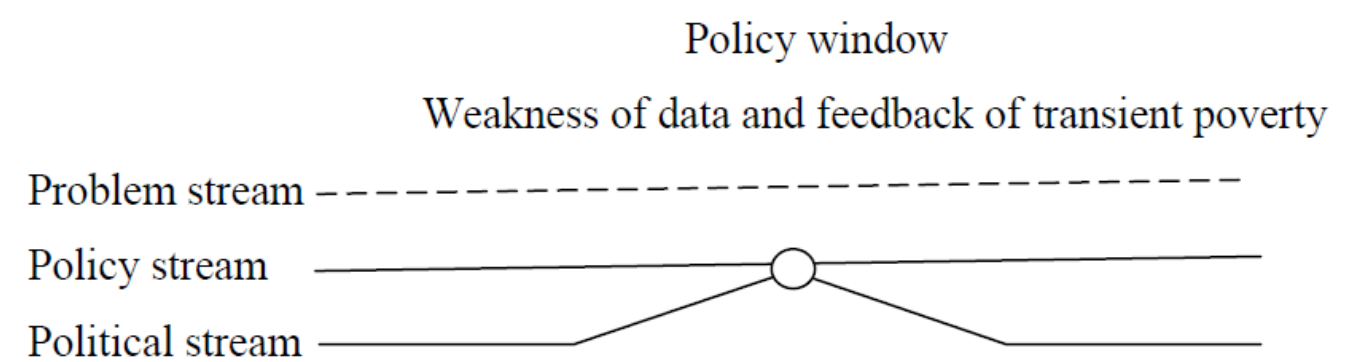

Weakness of Policy entrepreneur

Figure 3. Existing condition of the process of agenda-setting of transient poverty problem

By using the framework of Multiple Streams by Kingdon, Figure 3 explains the existing condition of the agenda-setting process in handling of transient poverty policies. This study noted that the problem stream, never encounter and being encountered with policy stream and political stream. The two streams, policy stream and political stream often encounter and being encountered but to articulate poverty problem in general. Transient poverty problem was never discussed specifically in the dialogue process. The encounter means to meet without involvement or intervention of policy entrepreneur, the three streams having the commitment to meet in order to solve the problem. While being encountered involves understanding the involvement or intervention of the policy entrepreneur in the stream and push all three to meet to resolve the problem by utilizing an open policy window.

There are some important notes from empirical data, such as: 1) the problem of transient poverty not becoming a mainstream in the problem stream, 2) the problem of recognition on the issue of transient poverty in the policy stream is weak, 3) the problem of recognition on the issue of transient poverty in the political stream is weak, and 4) the role of policy entrepreneur is also weak. Although there are many policy window openings, in fact there are no commitments of all the streams to encounter, thus there are also no strength and encouragement for all streams to be encountered.

Because there is no longitudinal data, a policy paper that could explain the 'what', 'who', 'why' and 'how' the problem of transient poverty and the problem of transient poor population groups, was not found. Because of differentiation in substance, the CBS grouping of poor population (very poor, poor, near-poor, the other vulnerable poor), or vulnerable poor by National Board for National Development Planning (Bappenas, 2006), or the near poor by National Team for Poverty Reduction Acceleration (TNP2K, 2011), cannot be used to explain the existence of the transient poor. Because policy makers do not know and understand the phenomena and issues of transient poverty, the handling of this issue did not get the recognition from the parties at the stage of agenda-setting process of poverty reduction policies. Significantly, there is no treatment that focuses on transient poor population. Substantively, the existence of the transient poor is not found in the statistical data of poverty. Schematically, the problem of transient poverty is also not found in 4 (four) clusters of poverty reduction policies. 


\section{Macrothink}

\section{Conclusion}

This study is aimed to ascertain the truth or untruth of allegations that problem of transient poverty has not been accommodated in the poverty reduction policy. Depth of study in exploring the position of transient population in the scheme of poverty reduction policy led to further search on the process of agenda-setting to find out reasons why a public issue can be accommodated or even ignored to be listed in the policy agenda. A convergence of logical thinking of research problems, logical thinking of theoretical framework, and empirical facts was deeply discussed in the discussion section. An intense dialogue on the logic of these have lead discussions in conclusion and recommendations.

There are two main findings that can be presented as the conclusion of this study. Firstly, the position of the transient poor population groups is outside the scheme of poverty reduction policies. Transient poor population is a group of people who experience poverty movement, namely poverty conditions specifically for individuals, families, or groups of people whose ability to finance the expenditure to be around, slightly below or above, and fluctuates up and down around the poverty line. Its mitigation cannot be confused with the handling of chronic poverty. Since the transient poor population have a moving characteristic, then its mitigation must be focused and specific. Specific handling for the transient poor population cannot be found in the scheme of poverty reduction policies. Schemes existing poverty reduction policies do not accommodate the interests and special handling for transient poor population due to the phenomenon of transient poverty issues are not clearly understood by policymakers, absence of longitudinal data, and perception bias of data confidentiality based on the Statistics Law No. 16 of 1997.

Secondly, the process of agenda-setting of poverty reduction policies is not scheduled to discuss the mitigation of the transient poor population. An abandonment to handle the problem of transient poverty has occurred since the agenda-setting stage in the process of formulation of poverty reduction policies. The abandonment of transient poverty issues in the agenda-setting process proved to be of no encounter of three streams: problem stream, policy stream, and political stream, even though the policy window opens frequently.

In particular, the neglect of this issue in the agenda-setting process can be explained as follows:

i). There are no recognition of the problem of transient poverty problem since the beginning. Problem recognition is the entry point of an issue into the public policy agenda. Because there are no problem-recognition, the understanding of the concept of transient poverty and the problem is weak and mingled with the understanding of chronic poverty. Because there is no recognition problem, then there is no consensus to handle the transient poverty problem as an alternative to poverty reduction policies.

ii). The problem streams to the problem of transient poverty is very weak. This is due to the weak understanding of the concept of transient poverty, weak indicators of longitudinal phenomenon of the transient poor which results in the absence of statistical data as the basis of dialogue, and content feedback is less significant as it describes the problem of poverty in general and disregards the many focusing events that actually provides inspiration for the opening of discussions on the subject of transient poverty; 
iii. The policy stream to the problem of transient poverty is very weak. This is due to: a) the weak understanding of the concept of transient poverty, b) the very dominant of cross-sectional data on the one hand and the absence of longitudinal data on the other side. As a matter of discussion, the weakness of policy community contribution policy and advocacy, weak policy entrepreneur, technical feasibility studies have yet to become a direction of policy research. There is no intense discussion about the political feasibility, and there is no consensus to make the problem of transient poverty as one of the mainstream of poverty reduction dialogue.

iv. The Political streams to the problem of transient poverty is very weak. This is due to: a) the weak understanding of the concept of transient poverty, b) unutilized of national mood to discuss the problem of transient poverty, c) the power of political organization that preoccupied with the issue of the political coalition and ignored the issue of poverty reduction in general, d) the election results conducive to open a new alternative for improvement poverty reduction policies, and e) there is no consensus to specially handling the problem of transient poverty.

\section{References}

National Board for National Development Planning (Bappenas). (2006). The potence of transient poverty in Indonesia in 2005. Majalah Info Kajian Bappenas, 3(1), 26-31.

Creswell, J. W. (1994). Research design: Qualitative and quantitative approaches. California: Sage Publications, Inc.

Creswell, J. W. (2013). Qualitative, quantitative, and mixed methods approaches (3rd ed.) Thousand Oaks California: Sage Publications.

Kingdon, J. W. (2014). Agendas, alternatives, and public policies (2nd ed.) Essex: Pearson Education Limited.

Ravallion, M. (1988). Expected poverty under risk-induced welfare variability. Economic Journal, 98, 1171-82. https://doi.org/10.2307/2233725

Ravallion, M. (1996). Issues in measuring and modelling poverty. The Economic Journal, 106, 1328-43. https://doi.org/10.2307/2235525

Santoso, P. (2010). Modul pembelajaran analisis kebijakan publik. Modul for public policy analysis and studies. Yogyakarta: Research Center for Politics and Government, Jurusan Politik dan Pemerintahan, Universitas Gadjah Mada.

Tim Nasional Percepatan Penanggulangan Kemiskinan (TNP2K). (2011). Program Penanggulangan Kemiskinan Kabinet Indonesia Bersatu II. Poverty alleviation program of the Indonesian Cabinet Unity II. Jakarta: Kementerian Kominfo.

United Nations Statistics Division. (2005). Handbook on poverty statistics: Concepts, methods, and policy use. Special Project on Poverty Statistics, United Nations Statistics Division.

Wilson, R. (2006). Analisis kebijakan sebagai saran kebijakan. In M. Michael, M. Rein, \& R. E. Goodin (Eds.), New York: Oxford University Press. Imam Baehaqie (penterjemah). 2015. Handbook kebijakan publik. Bandung: Penerbit Nusa Media. 


\section{Macrothink}

Journal of Social Science Studies

ISSN 2329-9150

\section{Copyright Disclaimer}

Copyright for this article is retained by the author(s), with first publication rights granted to the journal.

This is an open-access article distributed under the terms and conditions of the Creative Commons Attribution license (http://creativecommons.org/licenses/by/3.0/). 